\title{
“Kebunku” Educational Game Using Construct 2
}

\author{
Donna Apriana Sari \\ Software Engineering Technology, \\ Agricultural Management \\ Samarinda State Agricultural \\ Polytechnic \\ Samarinda, Indonesia \\ donna.apriana12@gmail.com
}

\author{
Yulianto \\ Software Engineering Technology, \\ Agricultural Management \\ Samarinda State Agricultural \\ Polytechnic \\ Samarinda, Indonesia \\ yulianto.tile@yahoo.com
}

\author{
Nisa Rizqiya Fadhliana \\ Software Engineering Technology, \\ Agricultural Management \\ Samarinda State Agricultural \\ Polytechnic \\ Samarinda, Indonesia \\ nisafadhliana@gmail.com
}

\begin{abstract}
Current sophistication of technology can educate devices outside the computer, and be applied to computers in the form of education. Games that have educational content are better known as educational games. This educational game aims to provoke children's interest in learning subject matter while playing games, and not focused on entertainment without any educational elements and the fun learning tool for children aged 7-8 years of elementary school. The development of this game using construct 2. Construct 2 uses the HTML 5 programming language and supports the development of 2-dimensional (2D) applications so that it is considered suitable for the game development process. The purpose of this research is to build an Educational Game "Kebunku" using Construct 2 which is played on a computer. The result of the "Kebunku" Educational Game is to learn the farming techniques going through by three stages, namely the process of planting fruit seeds, watering fruit seeds, and picking the fruit harvest.
\end{abstract}

Keywords-Application, Kebunku, Educational Game, Construct 2.

\section{INTRODUCTION}

The development of technology from year to year is very rapid, especially in the field of computers. One of the sophistications of technological developments today is the learning media influenced by various factors, one of which is the development of information technology. Along with the rapid development of information technology, a learning medium is now starting to be developed in the form of games.

According to (Noor, 2012) Gardening is one of the activities that can be used as a means of education. The problem currently faced is that children rarely own large tracts of land, making gardening or playing difficult. By utilizing the science of gardening technology, it can be done in electronic media which is packaged in the form of a program, namely gardening games.

Games that have educational content are better known as educational games. This educational type game aims to provoke children's interest in learning subject matter while playing games, and is not focused on entertainment alone without any educational elements and is a fun learning tool for children aged 7-8 years of elementary school.
The development of this game will use construct 2 as a means of making a game. Construct 2 uses the HTML 5 programming language and supports the development of 2-dimensional (2D) applications so that it is considered suitable for use in this game development process.

The research objectives of making this game are to build the My Garden Education Game application using Construct 2 which is played on a computer, to learn the techniques for making the "Kebunku" Educational Game using Construct 2 and the expected results in making this game include teaching children aged 7-8 years about the process. gardening from the My Garden Education Game Using Construct 2, this research is expected to provide benefits in the form of science, this research can be used as entertainment that is played on a computer.

\section{LITERATURE REVIEW}

\section{A. Scientific Study}

Some of the studies used as guidelines and references in this study include:

a) Research conducted by (Firdaus \& Nugroho, 2013) entitled Android-based Design of Educational Games for Brain Teasers for Children using the Construct 2 Application. Children's learning using interesting and fun game methods. By making this game, children can better remember and understand about counting and recognizing the names of objects. So that cognitive aspects that require greater thinking can be honed and children's creativity can increase by using Construct 2.

b) Research conducted by (Rostianingsih, 2013) entitled Design and Making Educational Games for My Farm and Animal Husbandry. This game is a life simulation genre emphasizing the freedom of the user to be able to do something in the game as in everyday life. At this time, it was rare for a pure game to have no mixed life simulation in it. Flash games that have sprung up with various genres on the internet, as well as support from 3rd party software for Adobe Flash.

c) Research conducted by (Gunawan, 2015) entitled Adventure Game Application for Children as Learning Media for Flora and Fauna in Indonesia in Indonesia. Flora and fauna learning games can help students in accelerating their understanding of knowledge about rare flora and fauna in Indonesia, 
increasing interest in interactive learning in the form of games that are equipped with multimedia. This game is specifically for elementary school children so that the learning stage can be more interesting. The design of a game cannot be separated from the software or an application, namely Construct 2 . This type of game is made an adventure game.

d) Research conducted by (Apriyanto \& Lasodi, 2016) entitled Making a Maze Game Using an Online-Based Construct 2 Application. This research is a development research research with an experimental approach. With the prototype development method, this study makes an online game with the arcade genre Maze Game title using the Construct 2 engine. This research produces a Maze Game that can be played online on all web browsers using HTML 5.

e) Research conducted by (Rahadi, Satoto, \& Windasari, 2016) entitled Math Adventure Game Design as an Android-based Mathematics Learning Media. Research on multimedia interactive learning applications with the theme of mathematics, to introduce mathematics to children in a fun and easy way to be absorbed on mobile media using Android. Research was conducted by Siti Mahampang (2017) with the title 3D Finding Treasure Educational Game Development as an assembly learning medium. computer for class X TKJ SMK students.

A comparison of several studies referred to in this study can be seen in table 1 .

Table 1. Study of Literature

\begin{tabular}{|c|c|c|c|}
\hline No. & Researcher & Service & Information \\
\hline 1. & $\begin{array}{l}\text { Silvia } \\
\text { Rostianingsih, } \\
\text { Hans Kristian } \\
\text { Wijaya, } \\
\text { Gregorius Satia } \\
\text { Budhi } \\
(2013)\end{array}$ & $\begin{array}{l}\text { Adobe Flash based } \\
\text { educational game. }\end{array}$ & $\begin{array}{l}\text { This skipsi focuses on } \\
\text { pure farming and } \\
\text { farming games } \\
\text { without any life } \\
\text { simulation mix. }\end{array}$ \\
\hline 2. & $\begin{array}{l}\text { Fendik } \\
\text { Gunawan } \\
(2013) \\
\end{array}$ & $\begin{array}{l}\text { Construct } 2 \text { based } \\
\text { educational game. }\end{array}$ & $\begin{array}{l}\text { This research focuses } \\
\text { on studying flora and } \\
\text { fauna in Indonesia }\end{array}$ \\
\hline 3. & $\begin{array}{l}\text { Apriyanto } \\
\text { Ishak Saputra } \\
\text { Lasodi } \\
(2016)\end{array}$ & $\begin{array}{l}\text { Constuct } 2 \text { based } \\
\text { Arcade game }\end{array}$ & $\begin{array}{l}\text { This study focuses on } \\
\text { an online maze } \\
\text { experiment approach. }\end{array}$ \\
\hline 4. & $\begin{array}{l}\text { Muhammad } \\
\text { Rizky Rahadi, } \\
\text { Kodrat Iman } \\
\text { Satoto, Ike } \\
\text { Pertiwi } \\
\text { Windasari } \\
(2016) \\
\end{array}$ & $\begin{array}{l}\text { Android Based } \\
\text { Educational Game }\end{array}$ & $\begin{array}{l}\text { This study focuses on } \\
\text { interactive learning } \\
\text { with the theme of } \\
\text { mathematics. }\end{array}$ \\
\hline 5. & $\begin{array}{l}\text { Muhamad } \\
\text { Firdaus, } \\
\text { Handang } \\
\text { Wahyu } \\
\text { Nugroho } \\
(2016) \\
\end{array}$ & $\begin{array}{l}\text { Construct } 2 \text { based } \\
\text { educational game }\end{array}$ & $\begin{array}{l}\text { This study focuses on } \\
\text { sharpening children's } \\
\text { brains. }\end{array}$ \\
\hline
\end{tabular}

B. Game

Game is a competition between players who interact with each other by using certain rules to achieve certain goals as well. In a game there must be competition so that players are stimulated to continue playing, this competition can take the form of winning and losing. Players must be able to find strategies or ways to solve problems so they can win the game. Games are games that use electronic media, which is a form of multimedia entertainment that is made as attractive as possible so that players can get something so that there is inner satisfaction. Playing games is a learning tool.

\section{Computer Games}

Computer games are different from games that are played on a game console (game console) such as starting from station, Xbox and so on. Although console games can also be played on a computer, if we run (play) on the console, the game cannot be called a console game. Computer games are also of many types, and from these computer games we can not only play with computer artificial intelligence, but we play games with friends (multiplayer), of course the computer we use to play this game must be connected, either by using a cable (LAN), WIFI and Internet.

Based on the type of platform or tool used:

a) Arcade Games, which are often called ding - dong in Indonesia, are usually in a special area / place and have a box or machine specifically designed for this type of video game.

b) PC games, namely video games played using Personal Computers.

c) Console Games, namely video games that are played using certain consoles, such as Mulaistation 2, Mulaistation 3, and Nintendo Wii.

d) Handheld Games, which are played on a special console for video games that can be taken anywhere, for example the Nintendo DS and Sony PSP.

e) Mobile Games, which can be played or specifically for mobile phones or PDAs.

Several types of games and examples are:

a) Educational Games

b) Entertainment

Games whose purpose is just entertainment, for example:
a) Action (Shooting)
b) Fighting (Fighting)
c) Adventure
d) Role Starting
e) Casual Games
f) Online Multi Starter

\section{Educational Games}

Educational games are one type of media used to provide teaching, add user knowledge through a unique and interesting medium. This type is usually intended for children, so the color game is really needed here, not the level of difficulty that is important. Based on the description above, it can be concluded that educational games are a form of games that can be useful to support the teaching-learning process in a more fun and creative way, and are used to provide instruction or increase user knowledge through an interesting medium. 


\section{E. Game}

Games can be defined as problem-solving activities, approached with a pleasant attitude, games are also something that makes players find pleasure in playing them. Good games are games that can make users actively participate and have the right number of challenges, not too few or too many. Games are selfexercising efforts (mind and physical exercise) which are very beneficial for the improvement and development of motivation, performance and achievement in carrying out the tasks and interests of the organization better. Games are more often played by children, but nowadays adults also like to play games and keep up with the current games (Martono 2015).

\section{F. Programming Language}

Programming languages or often termed computer languages or computer programming languages, are standard instructions for commanding computers. This programming language is a set of syntax and semantic rules that are used to define computer programs. This language allows a programmer to determine exactly which data the computer will process, how this data will be stored / transmitted, and exactly what types of steps will be taken in various situations.

\section{G. HTML 5}

HML5 stands for Hypertext Markup Language version 5, is a new HTML successor to HTML 4, XHTML1, and DOM Level 2 HTML. HTML5 is the development of a better, more meaningful or semantic HTML language, which was previously a simple markup language into a sophisticated, feature-rich and rich platform called application programming interface.

\section{H. Construct 2}

Construct 2 is an HTML5-based game maker application specifically for the 2D platform developed by Scirra (Silalahi, 2017). Construct 2 does not use a special programming language, because all commands used in the game are arranged in the Even Sheet which consists of Events and Actions. Some of the advantages of using contruct 2, namely:
a) Quick and Easy
b) Powerful Event System
c) Flexible Behaviors
d) Instant Preview
e) Stunning Visual Effects
f) Multiplatform Export
g) Easy Extensibility

\section{RESEARCH METHODS}

The following describes the research object, methods and stages of the research conducted;

\section{A. Tools and Materials}

Tools used:

a) Laptop (8GB DDR4 Memory Ram, Intel CORE i7, 1TB HDD, 14.0 HD LCD).

b) Internet Access
Materials to be used in this research are as follows:

a) Construct 2

b) Research Procedure

c) Study Literature

d) The collection of references related to this research is like the construct 2 reference:

1. Collecting data in the form of sources and material about the knowledge of plantation plants and fruit objects in the form of images downloaded on the internet.

2. Create a game flow.

3. Create a storyboard design.

4. Installing Construct 2.

5. Making Applications according to the Storyboard.

6. Fixes if there are problems with this application, fixes will be made to the problems that occur.

7. Game testing.

8. Tester laptop (4GB DDR3 Memory Ram, 500GB HDD, 14.0 HD LED LCD).

B. Storyboard

The following storyboard of the research conducted:

a) Figure 1 shows, the main page display of the application contains Start to start the game, Game Guide, and Settings.

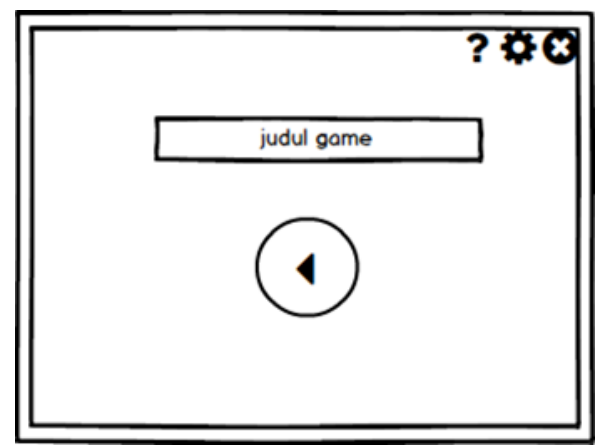

Figure 1. Main Page Display

b) Figure 2 shows, game guide display

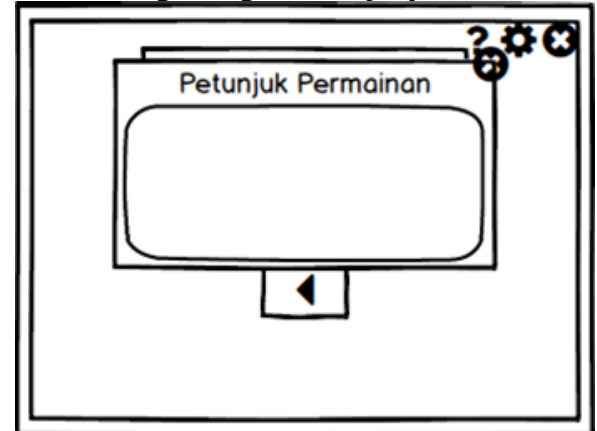

Figure 2. Game Guide Display 
c) Figure 3 shows, display settings

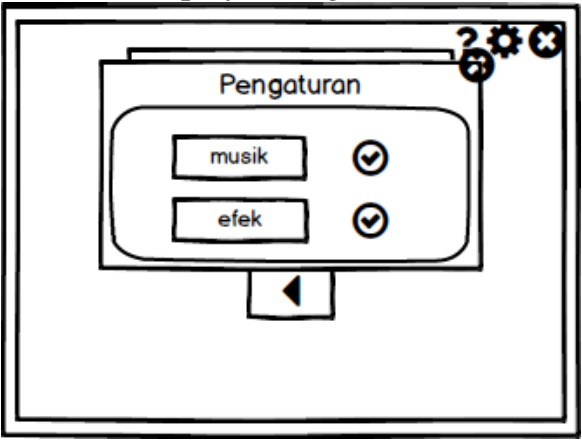

Figure 3. Dipslay Setting

d) Figure 4 shows, level 1 display

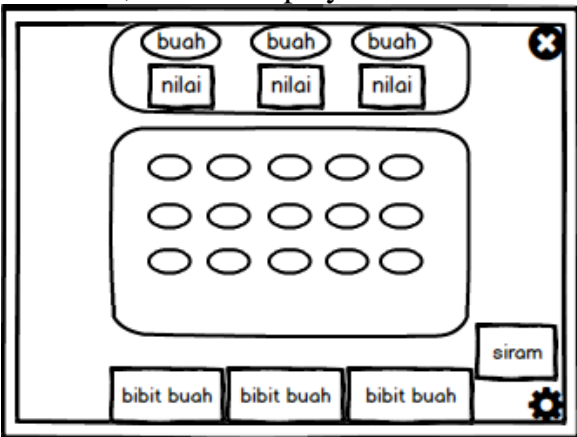

Figure 4. Level 1 Display

e) Figure 5 shows, level 2 and level 3 display

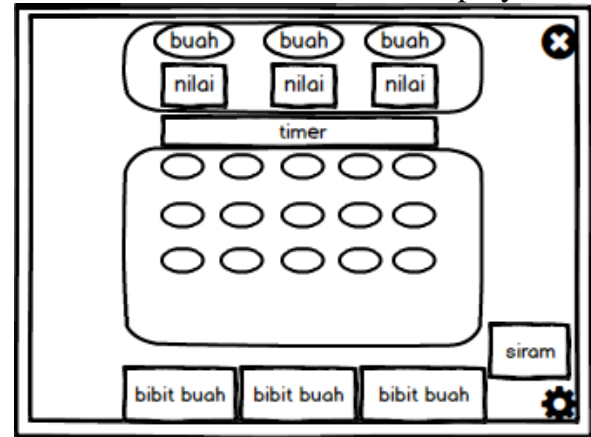

Figure 5. Level 2 and 3 Display

f) Figure 6 shows, display successful

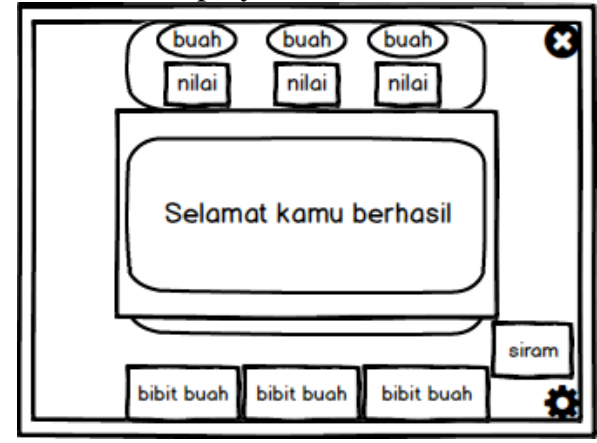

Figure 6. Display Successful g) Figure 7 shows, display failed

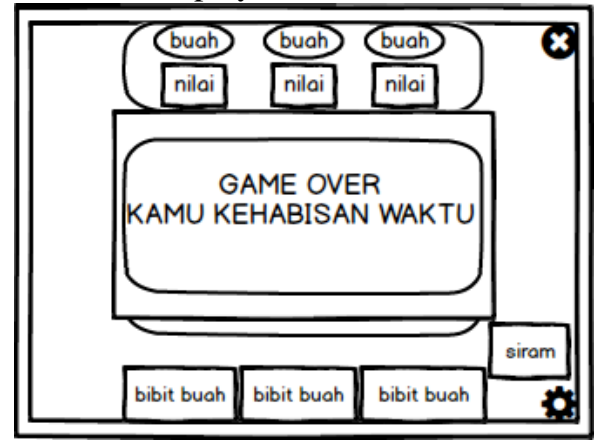

Fiugre 7. Display Failed

h) Figure 8 shows, display exit

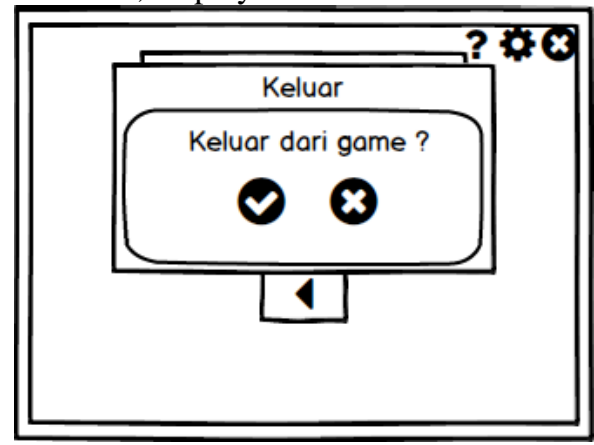

Figure 8. Display Exit

IV. RESULTS AND DISCUSSION

A. Result

The following are the results of the "Kebunku" Educational Game application using Construct 2:

a) Main Menu Page

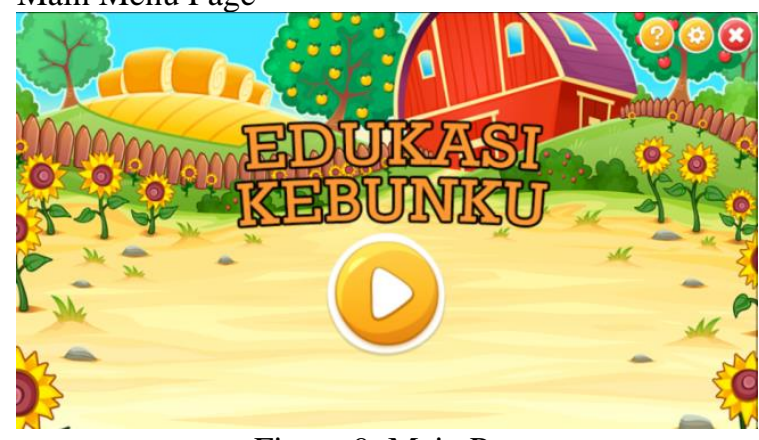

Figure 9. Main Page

The main menu is the main page in the game which contains the title with a button or start button, game instructions, settings, and exit. 
b) Setting Page

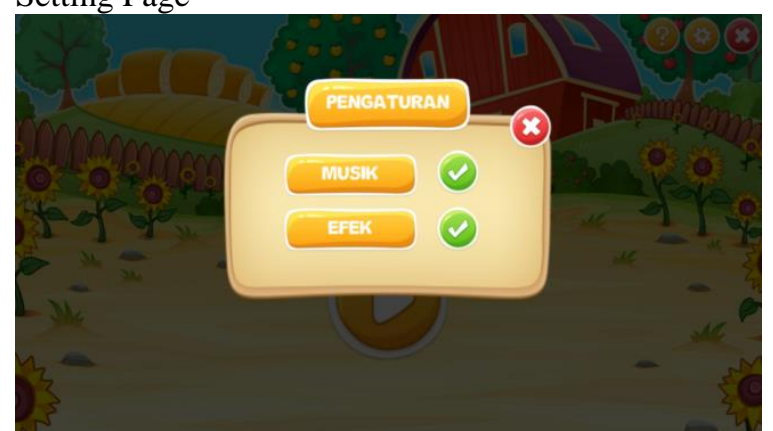

Figure 10. Setting

The Settings page is a menu that displays settings to mute or turn on audio such as music and effects to users.

c) Game Instruction Page

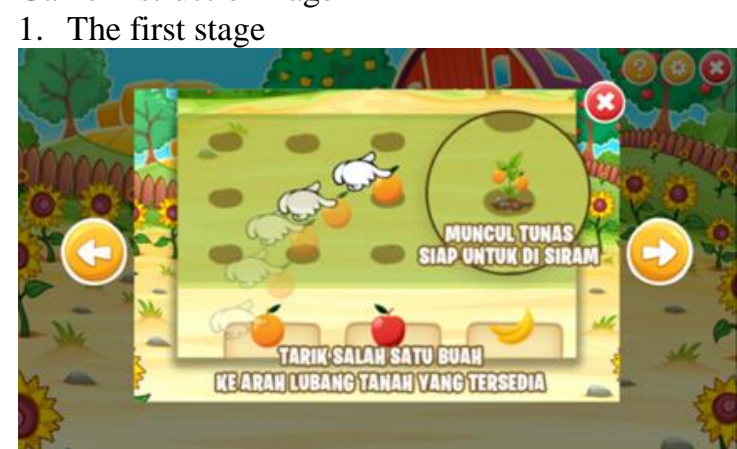

Figure 11. Stage One Game Instructions

The game manual page is a menu that displays game instructions from the first stage, namely selecting fruit seeds to be planted and small shoots will appear.

\section{Second stage}

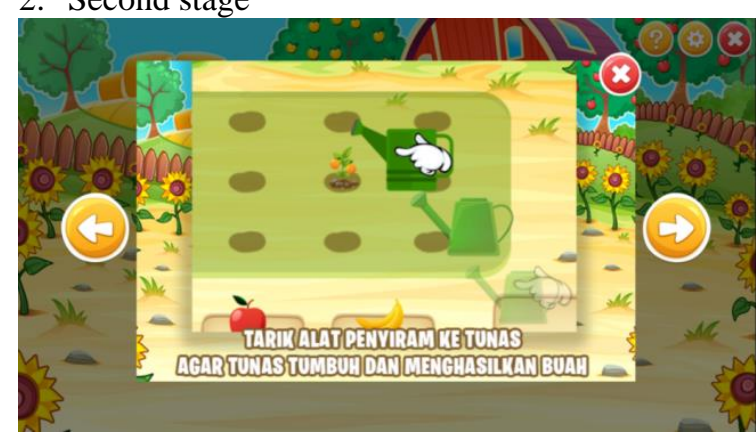

Figure 12. Second Stage Game Instructions

The second stage is watering the shoots with a water pot.
3. Third stage

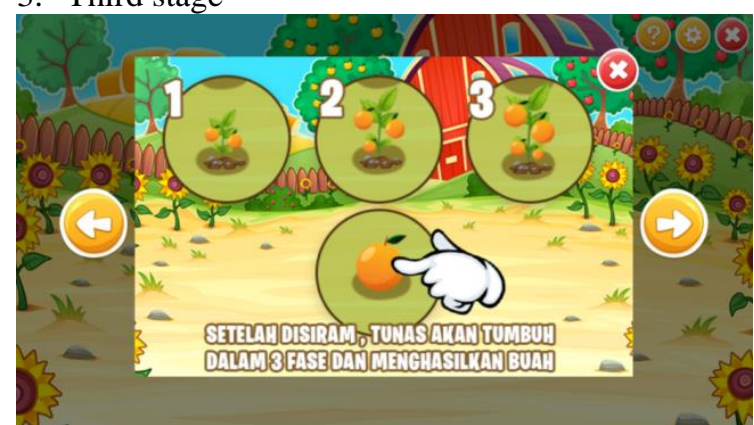

Figure 13. Stage Three Game Instructions The third stage is that the shoots that have been watered will grow into large shoots and become fruit ready to be picked.

\section{Fourth stage}

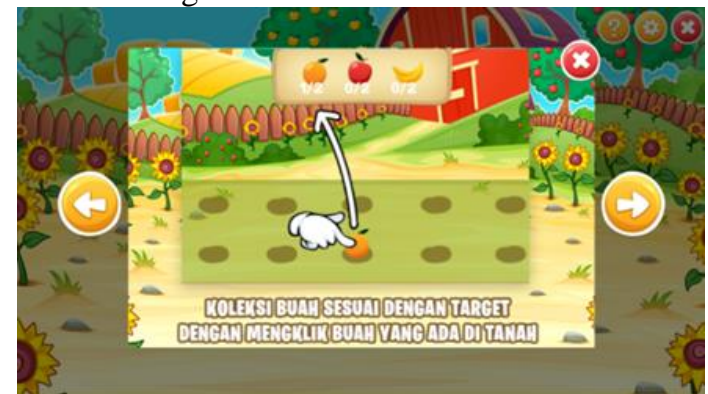

Figure 14. Stage Four Game Instructions

d) Level 1 Page

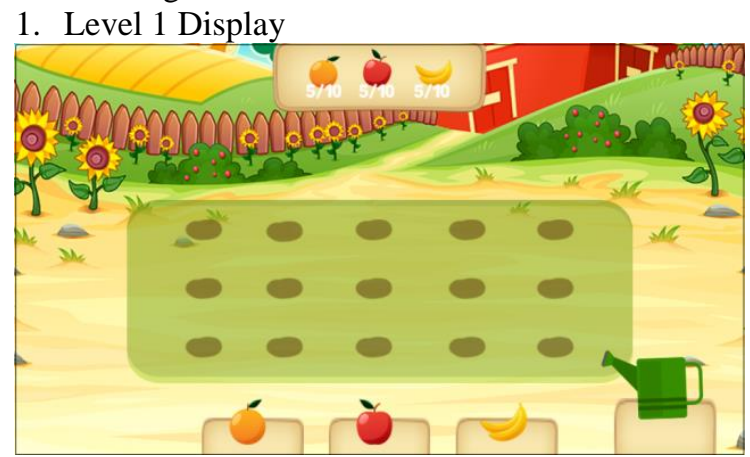

Figure 15. Page Level 1

The level 1 page contains a garden courtyard view with 15 soil holes, several choices of fruit seeds, a pot filled with water for watering the seeds, and a fruit scoreboard.

2. Planting Fruit Seeds

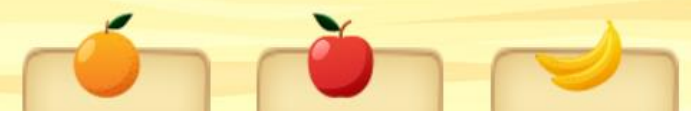

Figure 16. Display of Fruit Options

When going to plant fruit seeds, the first thing to do is choose fruit seeds that will be planted in the available soil holes. Some of the fruit seeds in Level 1 are at the bottom of the screen. Then plant the fruit seeds that have been selected by bringing the fruit seeds to the soil hole which will be planted with fruit seeds and 
placing the fruit seeds right in the hole where the fruit seeds will be planted.

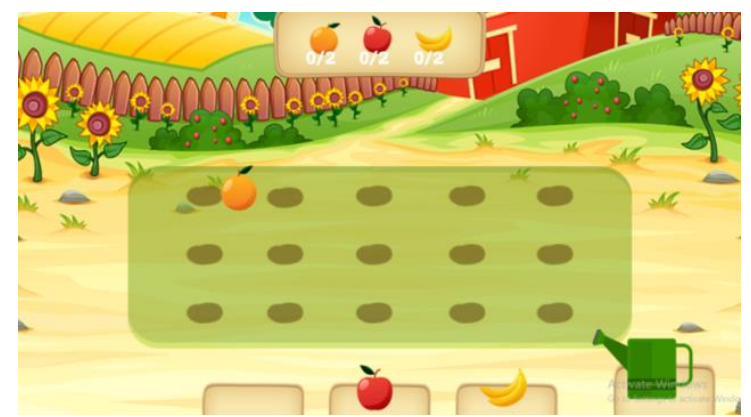

Figure 17. Putting Fruit seeds in the Soil Hole

If you succeed in placing the fruit seeds right in the soil hole, the fruit planted will turn into small shoots

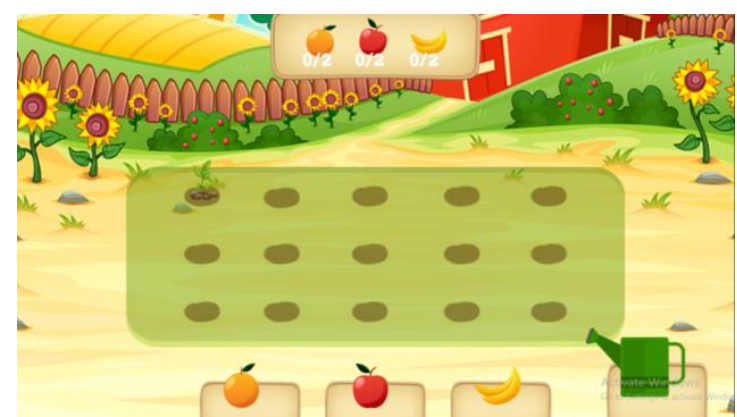

Figure 18. Fruit Seeds Become Small Shoots

e) Watering the Seeds

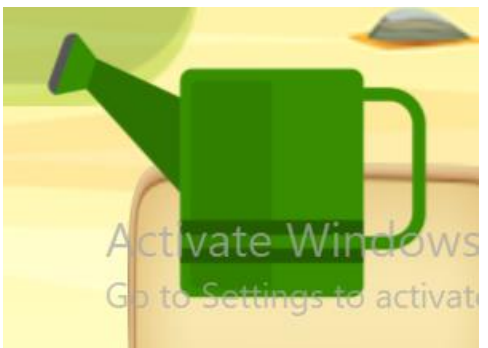

Figure 19. Water Pot

When the seeds have been planted, the next step is to take care of them by watering the shoots with the water pot that is on the far right of the game display.

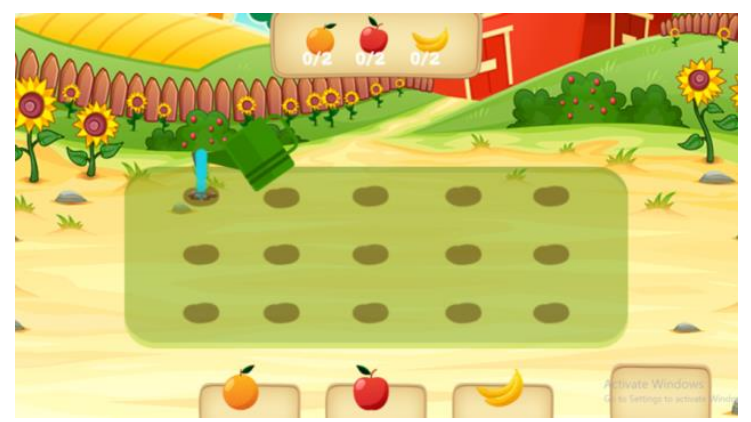

Figure 20. Watering the Shoots

The way to water it is to bring and put a water pot right above the shoots in the soil if the water pot is placed correctly, the pot will release water and hit the planted shoots as well as if the pot is placed incorrectly the pot will return to its original place.

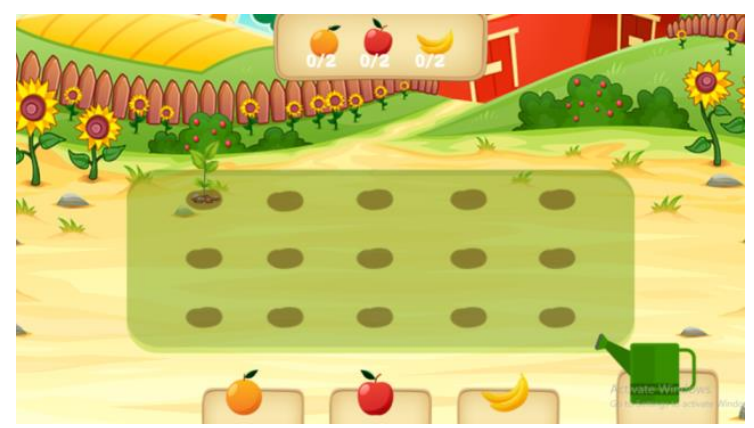

Figure 21. The Shoots Grown Bigger

After watering the shoots, the shoots will grow bigger.

f) Yields

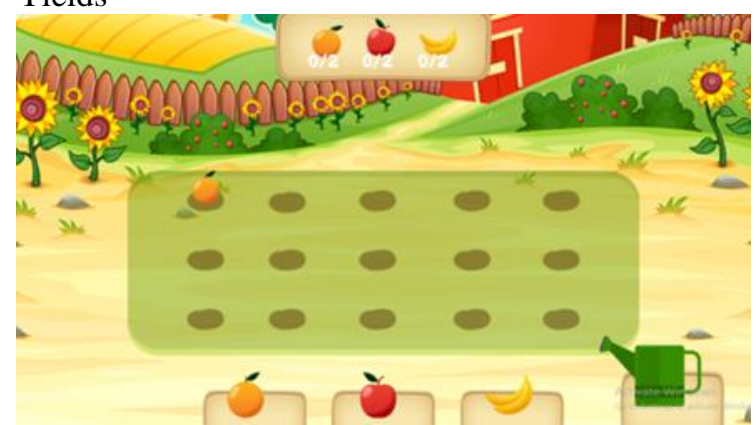

Figure 22. The Appearance of Shoots Becoming Fruit

After the shoots grow bigger, they will turn into fruit on the surface of the hole or soil.

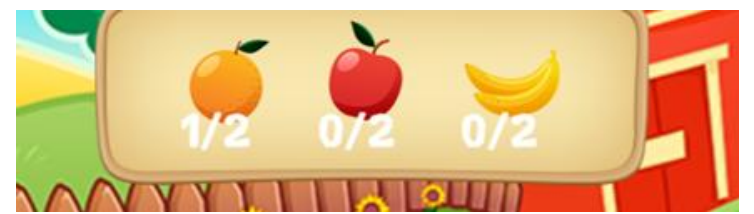

Figure 23. Score

And the final step is picking the harvest by touching right on the fruit that has been harvested from the shoots that have grown to be large and the value score will increase with the value of each fruit which is 2 , then the total fruit to be harvested is 6 .

g) Level 2 Page

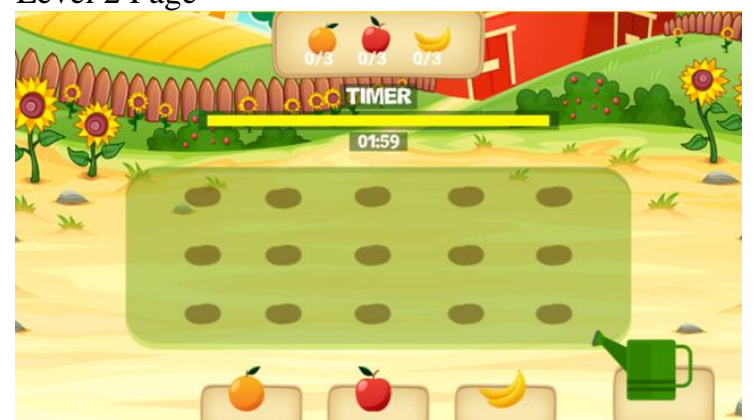

Figure 24. Page Level 2 
The page at level 2 contains the same display as level 1 , which distinguishes only the level of difficulty, namely the time limit for completing the game for 2 minutes. The fruit score that must be collected at level 2 is 3 and the total of all fruits is 9 and there is a predetermined time in completion.

h) Level 3 Page

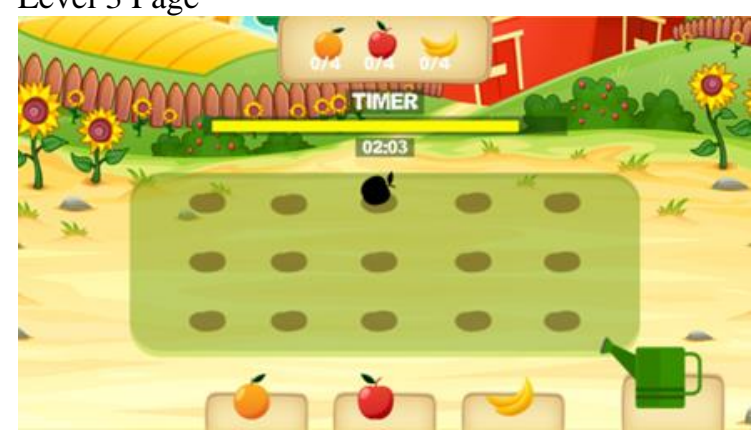

Figure 25. Page Level 3

The page at level 3 contains the same appearance as level 2 which distinguishes only the level of difficulty, namely the time limit for completing the game for 2 minutes 20 seconds and if within 5 seconds the fruit will rot until it disappears.

i) Success Page

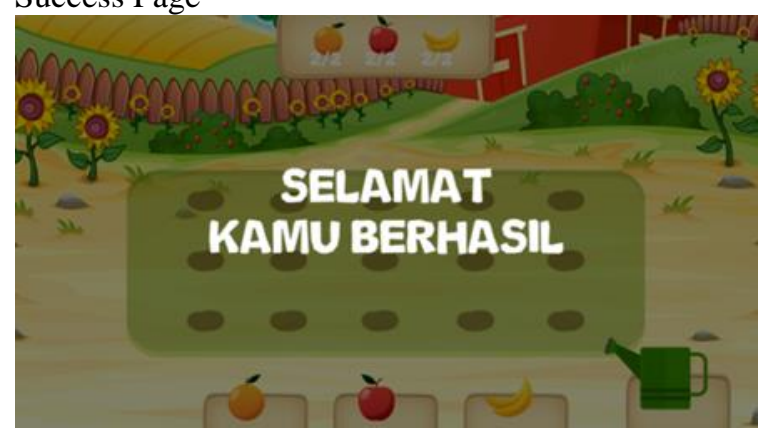

Figure 26. Page Successful

The success page displays a notification that has successfully completed each game level.

j) Page Failed

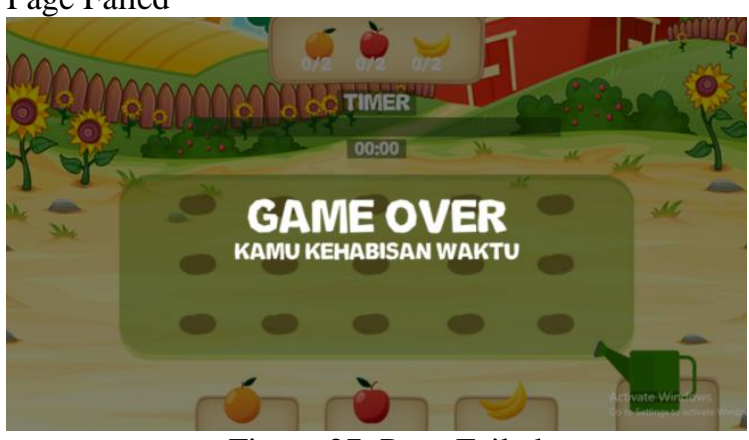

Figure 27. Page Failed

The failed page displays a notification that it failed or failed to complete each level. k) Exit Page

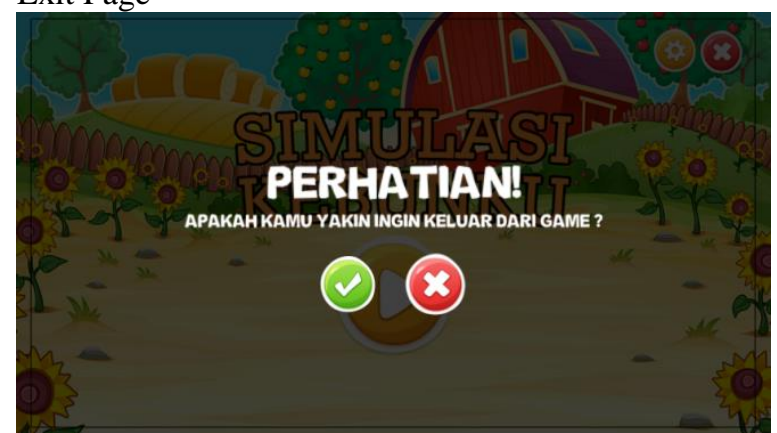

Figure 28. Exit Page

The Exit page contains a display of the cancel exit option, which is to remain in the game. And if you choose to exit it will exit the game closing the application.

\section{B. Testing}

The following are the results of the tests conducted by the author:

\begin{tabular}{|c|c|c|}
\hline Component & Expected results & Result \\
\hline Button Start & $\begin{array}{l}\text { Clicking the button will enter the } \\
\text { level selection layout page in the } \\
\text { game }\end{array}$ & It works \\
\hline $\begin{array}{l}\text { Button Game } \\
\text { Instructions }\end{array}$ & $\begin{array}{l}\text { Clicking the button will enter the } \\
\text { Game Guide Layout Page }\end{array}$ & It works \\
\hline Button Settings & $\begin{array}{l}\text { Clicking the button will enter the } \\
\text { Settings Layout Page }\end{array}$ & It works \\
\hline Button Exit & $\begin{array}{l}\text { Clicking the button will exit the } \\
\text { game }\end{array}$ & It works \\
\hline $\begin{array}{l}\text { Button choice of } \\
\text { level }\end{array}$ & $\begin{array}{l}\text { Clicking the button will enter the } \\
\text { game with the selected level of } \\
\text { choice }\end{array}$ & It works \\
\hline $\begin{array}{l}\text { Button Menu on } \\
\text { Layout Stage } \\
\text { Level }\end{array}$ & $\begin{array}{l}\text { Clicking the Button will enter the } \\
\text { Level Selection Layout Page }\end{array}$ & It works \\
\hline $\begin{array}{l}\text { Button Main } \\
\text { course }\end{array}$ & $\begin{array}{l}\text { ButtonThis will appear if the } \\
\text { player loses } 3 \text { lives. Clicking the } \\
\text { button will go to the Main Page } \\
\text { menu }\end{array}$ & It works \\
\hline
\end{tabular}

The conclusion from the application test table is that the buttons in the application function properly and are in accordance with the expected results.

Testing the instructional media for the "Kebunku" Educational Game Using Construct 2 was conducted at SD Negeri 001 Samarinda Seberang for grade 1 elementary school students with a total of 38 students and female students. To find out the function of my garden educational game, a questionnaire is used. Testing in the form of a questionnaire consists of 4 questions distributed to 38 respondents. Based on the data from the questionnaire, you can find the percentage of each answer with the (1) 
$\mathrm{Y}=\mathrm{P} / \mathrm{Q} * 100$

Information(1)

$\mathrm{Y}=$ Percentage Value

$\mathrm{Q} \quad=$ Number of Respondents

$\mathrm{P} \quad=$ The number of respondents' answers to each Question

The following is the number of respondents for each question:

Table 3. Weighted Value

\begin{tabular}{|c|c|}
\hline \multicolumn{2}{|c|}{ Weight Value } \\
\hline Like it & 1 \\
\hline Do not like & 0 \\
\hline
\end{tabular}

Table 4. Number of Respondents

\begin{tabular}{|c|l|c|c|}
\hline \multirow{2}{*}{ No. } & \multicolumn{1}{|c|}{ Question } & \multicolumn{2}{|c|}{ Percentage Eligibility } \\
\cline { 3 - 4 } $\mathbf{1}$ & $\begin{array}{l}\text { Like it } \\
\text { Are you interested in } \\
\text { using this My Garden } \\
\text { Educational Game? }\end{array}$ & $\mathbf{3 3}$ & $\mathbf{5}$ \\
\hline $\mathbf{2}$ & $\begin{array}{l}\text { Is the appearance of like } \\
\text { My } \\
\text { Educational Game } \\
\text { attractive? }\end{array}$ & $\mathbf{3 5}$ & $\mathbf{3}$ \\
\hline $\mathbf{3}$ & $\begin{array}{l}\text { Is this My Garden } \\
\text { Educational Game } \\
\text { easy to play? }\end{array}$ & $\mathbf{3 5}$ & $\mathbf{3}$ \\
$\mathbf{4}$ & $\begin{array}{l}\text { Do you think the } \\
\text { Gamen Pendidikan } \\
\text { students are } \\
\text { interesting to use for } \\
\text { learning? }\end{array}$ & $\mathbf{3 5}$ & $\mathbf{3}$ \\
\hline
\end{tabular}

Based on the results of the questionnaire that has been calculated from the total results of student respondents who are interested in my garden educational game is $90.78 \%$ and those who are not interested in my garden educational game are $9.21 \%$.

\section{CONCLUSION}

Based on the results and discussion, it can be concluded that the "Kebunku" Educational Game is a collection of data in the form of sources and material about the knowledge of plantation plants and fruit objects in the form of images downloaded on the internet, making game flow, making storyboard designs, installing construct 2, making appropriate applications storyboard, improvements if there are problems with this application, repairs will be made to problems that occur, game testing, implementation, the My Garden Educational Game has three stages, namely the process of planting fruit seeds to be planted, watering as a form of care for planted fruit seeds, and picking the results harvest fruit by the specified value score. My Garden Educational Game has 3 levels, namely the first level, the second level, and the third level. First level, second level.

It is hoped that the My Kebunku Educational Game can add a deep level of difficulty to avoid boredom in playing the "Kebunku" Educational Game. It is hoped that "Kebunku" Educational Game can add players from one player to two to three players.

\section{REFERENCES}

Aninda Nabilla. (2015). Development of Journal Material Education Game.

Apriyanto, A., \& Lasodi, IS (2016). Making a Maze Game Using an Online-Based Construct 2 Application. Electronic Journal of Information Systems and Computers, 2 (2), 64-72.

Bunafit, Nugroho. (2004). PHP and MySQL with Dreamweaver MX editor. Yogyakarta: ANDI.

Firdaus, M., \& Nugroho, HW (2013). Design and Build an Android-Based Educational Game for Children Using Construct 2, 1-10.

Gunawan, F. (2015). Adventure Game Application for Children as Learning Media for Flora and Fauna in Indonesia Fendik. J-Intech, 03 (01), 52-55.

Martono, KT (2015). Game development using, 5 (1), 23-30.

Noor, AS (2012). Designing and manufacture of "tasya plantation" game using adobe flash cs5.

Plants: https://www.freepik.com/free-vector/green-plantgrowing-from-underground_2956132.htm

Rahadi, MR, Satoto, KI, \& Windasari, IP (2016). Designing a Math Adventure Game as a Mathematics Learning Media Based on Android. Journal of Technology and Computer Systems, 4 (1), 44. https://doi.org/10.14710/jtsiskom.4.1.2016.44-49

Reserve Fruit: https:/www.freepik.com/free-vector/greatset-colored-fruits-flat-design_1103415.htm

Rostianingsih, SHKWGSB (2013). Design and Development of Agriculture and Livestock Simulation Games, (2005), 1-6.

Silalahi, DR (2017). Game "Catch Me" Using the Game Engine Contruct 2 Based on Uml Diagram, 35.

Sprinkler:https://www.freepik.com/freevector/agriculture -icons-set_4407295.htm

Subhan M. (2012). Analysis of System Design. Lentera Ilmu Cendekia: Jakarta 